\title{
LEVANTAMENTO FLORÍSTICO E FITOSSOCIOLÓGICO EM REMANESCENTE FLORESTAL EM PATOS-PB
}

Floristic and phytosociological survey in forest remnant, in Patos-PB

Encuesta florística y fitosociológica de restante forestales en Patos-PB

\section{Natielly Cristine Gomes de Medeiros ${ }^{1}$, Savio Maciel da Silva Sousa ${ }^{1}$, Mikaella Meira}

\author{
Monteiro $^{1}$, Lucas Kelvy Sales Azevedo ${ }^{2}$, Francisco das Chagas Vieira Sales*1 \\ ${ }^{1}$ Unidade Acadêmica de Engenharia Florestal, Centro de Saúde e Tecnologia Rural, Universidade Federal de \\ Campina Grande, Patos-Paraíba, Brasil \\ ${ }^{2}$ Departamento de Biologia, Bacharelado em Ciências Biológicas, Universidade Estadual da Paraíba, Campina \\ Grande-Paraíba, Brasil. \\ *Correspondência: Unidade Acadêmica de Engenharia Florestal, Centro de Saúde e Tecnologia Rural, \\ Universidade Federal de Campina Grande, CEP 58708-110, Patos-Paraíba, Brasil. e-mail \\ franciscoef@yahoo.com.br
}

\section{RESUMO}

O objetivo deste trabalho foi avaliar a composição florística e a estrutura da vegetação através da amostragem por ponto quadrante. $\mathrm{O}$ trabalho foi realizado no Horto Florestal da Universidade Federal de Campina Grande, Campus de Patos - PB, com área aproximada de 1,6 hectares. Em cada ponto, foi amostrado um indivíduo por quadrante que apresentaram circunferência a altura do peito $\geq 6 \mathrm{~cm}$, registrando-se os nomes comuns, CAP's e altura total. Foram analisadas a composição florística, os parâmetros fitossociológicos, a estrutura diamétrica e a estimativa de produção. A fitossociologia foi representada por 12 espécies, 12 gêneros, distribuídas em 6 famílias. A família com maior riqueza foi Fabaceae, com seis espécies e 73 indivíduos. O índice de Shannon $\left(\mathrm{H}^{\prime}\right)$ foi de 2,12 nats.ind ${ }^{-1}$, e equabilidade de Pielou (J) foi 0,85. A espécie Prosopis juliflora apresentou o maior valor de importância e maior número de indivíduos, seguida da Leucaena leucocephala. O maior número de indivíduos foi registrado nas primeiras classes de diâmetro. A predominância de P. juliflora e L. leucocephala afetam o desenvolvimento e regeneração das espécies nativas na área.

Palavras-chave: Ponto quadrante, caatinga, diversidade.

\section{ABSTRACT}

The objective of this work was to evaluate the floristic composition and the vegetation structure through the sampling by quadrant point. The work was carried out at the Horto Florestal of the Federal University of Campina Grande, Campus de Patos - PB, with an area of approximately 1.6 hectares. At each point, an individual per quadrant was sampled who had a breast height circumference $\geq 6 \mathrm{~cm}$, registering common names, CAP's and total height. The floristic composition, the phytosociological parameters, the diametric structure and the production estimate were analyzed. Phytosociology was represented by 12 species, 12 geners, distributed in 6 families. The family with the greatest wealth was Fabaceae, with six species and 73 individuals. The Shannon index $\left(H^{\prime}\right)$ was 2.12 nats.ind ${ }^{-1}$, and the Pielou (J) equability was 0.85 . The Prosopis juliflora species had the highest importance value and the largest number of individuals, followed by Leucaena leucocephala. The largest number of individuals was registered in the

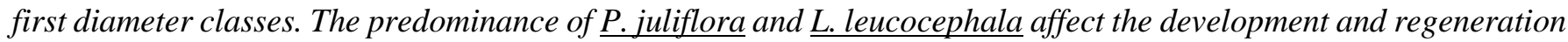
of native species in the area.

Keywords: Quadrant point, caatinga, diversity. 


\section{RESUMEN}

El objetivo de este trabajo fue evaluar la composición florística y la estructura de la vegetación mediante muestreo por punto cuadrante. El trabajo se llevó a cabo en el Horto Florestal de la Universidad Federal de Campina Grande, Campus de Patos-PB, con 1.6 hectáreas de área. En cada punto, se tomó una muestra de un individuo por cuadrante que tenía una circunferencia a altura del pecho $\geq 6 \mathrm{~cm}$, registrando nombres comunes, CAP y altura total. Se analizó la composición florística, los parámetros fitosociológicos, la estructura diametral y la estimación de producción. La fitosociología estuvo representada por 12 especies, 12 géneros, distribuidos en 6 familias. La familia con mayor riqueza fue Fabaceae, con seis especies y 73 individuos. El indice de Shannon ( $\left.H^{\prime}\right)$ fue 2.12 nats.ind ${ }^{-1}$, y la igualdad de Pielou (J) fue 0.85. La especie Prosopis juliflora tuvo el mayor valor de importancia y el mayor número de individuos, seguida de Leucaena leucocephala. El mayor número de individuos se registró en las clases de primer diámetro. El predominio de P. juliflora y L. leucocephala afecta el desarrollo y la regeneración de especies nativas en el área.

Descriptores: Punto cuadrante, caatinga, diversidad.

\section{INTRODUÇÃO}

O Bioma Caatinga é um ecossistema unicamente brasileiro, ocupando cerca de $11 \%$ do território nacional, que predomina no estado do Ceará, Piauí, Paraíba, Pernambuco, Rio Grande do Norte, Bahia e em menor extensão nos estados de Minas gerais, Alagoas, Sergipe (Andrade et al., 2005; Leal et al., 2005).

Esta vegetação com predominância de arbustos espontâneos, retorcidos, de aspecto seco, densos, baixos, predominam em solos rasos e pedregosos, relativamente férteis, ricos em recursos genéticos e alta biodiversidade (Duque, 2004; Pessoa et al., 2008).

A caatinga é essencial aporte às necessidades das populações instaladas, principalmente na zona rural, de forma complementar às atividades produtivas, a caatinga é submetida ao longo do tempo, a explorações de várias formas e para diversos fins, frequentemente de forma desordenada e sem as medidas necessárias à sua manutenção.

Dentre os principais usos da vegetação na Caatinga, o principal produto é a lenha, mesmo com o baixo valor agregado obtido pela lenha, o fácil acesso e o mercado consumidor, tornam a demanda por este produto muito atrativa, se tornando uma ameaça a biodiversidade da região. De acordo com dados apresentados por Ndagijimana et al., (2015), a Paraíba perdeu mais de $45 \%$ da vegetação de caatinga até 2009 .
Essas atividades produtivas podem ser adotadas em regimes mais adequados e planejados de uso da vegetação nativa, através do manejo florestal. Como forma de orientar ações de manejo, recuperação ou mesmo preservação desta vegetação, recorre-se inventários florestais. Segundo Chaves et al., (2013), estudos que possibilitam conhecer a flora e a estrutura da vegetação, são essenciais na tomada de decisões acerca do uso, conservação e recuperação de áreas, recorrendo-se aos métodos amostrais para obtenção destas informações.

Brito et al., (2007), relatam que os métodos de amostragens com parcelas de área fixa e o método de ponto quadrantes, são os mais utilizados em florestas nativas. O método de ponto quadrante é de rápida alocação e baixo custo para o inventário florestal, além da redução do erro amostral por não ter árvores limite, em relação aos de áreas fixa, sendo portanto recomendado como eficiente e produz resultados confiáveis (Mitchell, 2015; Oliveira et al., 2015).

Assim, o objetivo deste trabalho foi avaliar a composição florística e a estrutura da vegetação através da amostragem pelo método dos quadrantes.

\section{MATERIAIS E MÉTODOS}

O trabalho foi realizado no Horto Florestal da Universidade Federal de Campina Grande - UFCG, campus de Patos $-\mathrm{PB}$, nas coordenadas geográficas: $\mathrm{S}$ 
7¹3’08” e O 3554'05" (Araújo et al., 2018), em fragmento florestal com área de 1,6 hectares (Fig. 1). A região apresenta regime pluviométrico de $715,3 \mathrm{~mm}$ e temperatura média anual entre $27^{\circ} \mathrm{C}-28^{\circ} \mathrm{C}$ (BRASIL, 2005).

Figura 1. Localização do Horto Florestal da UFCG - Patos

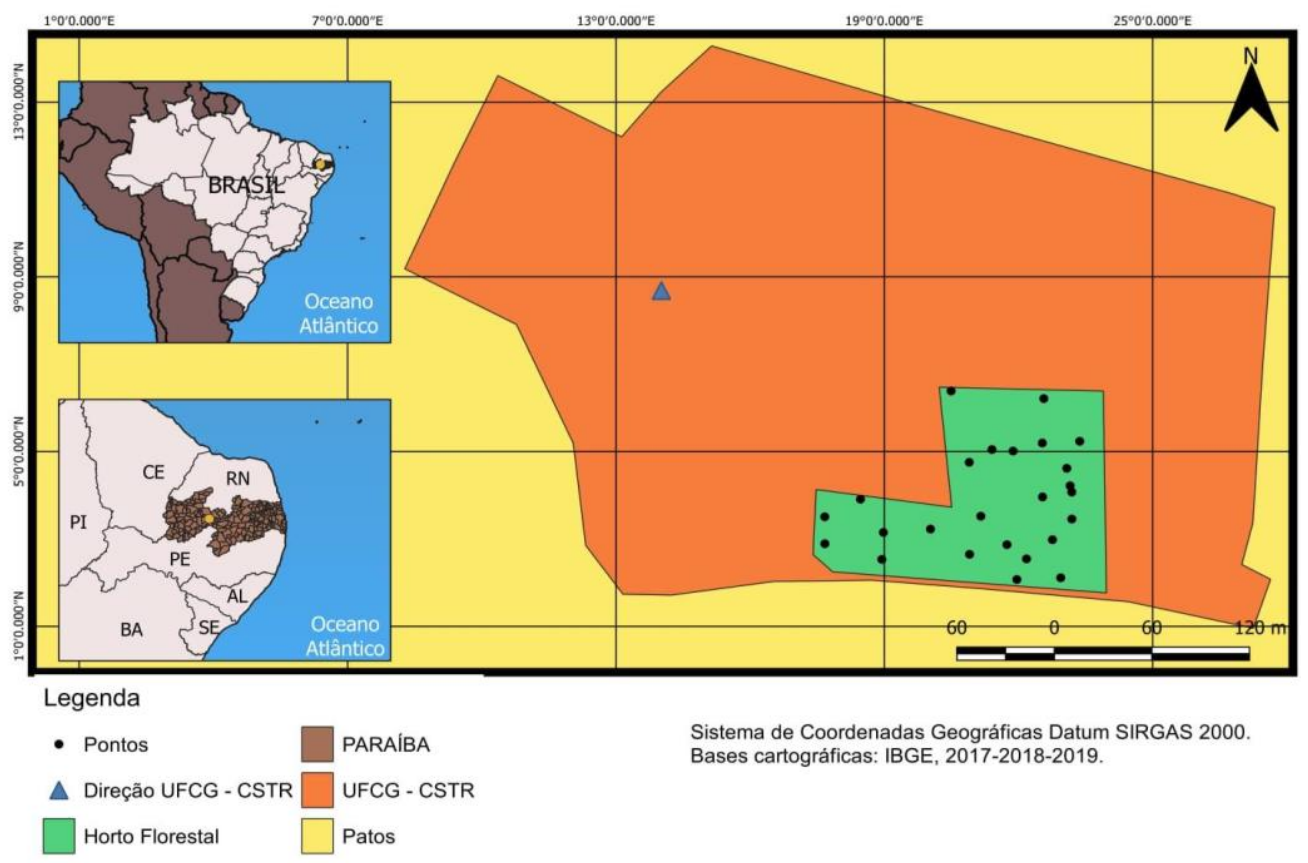

Para a realização do levantamento do componente arbóreo foi empregado o método de quadrantes (Cottam e Curtis, 1956), o qual consistiu no estabelecimento de 25 pontos amostrais, georreferenciados e distribuídos aleatoriamente, dividiu-se a área ao redor deles em quatro quadrantes, medindo a distância do centro do ponto até a árvore ou arbusto mais próximo que apresentava circunferência a altura do peito (CAP $1,3 \mathrm{~m}$ do solo) $\geq$ a $6 \mathrm{~cm}$ em cada quadrante, cuidando para que um indivíduo não fosse remedido em outro ponto amostral, bem como também registrando-se os nomes comuns, CAP's e altura total de cada indivíduo.

O reconhecimento das espécies foi realizado in loco, baseando-se nas características dendrológicas presentes, tais como, fruto, folhas, casca. Em seguida, foram feitas consultas à Maia (2004) e no site da Flora
Brasil (2020), com posterior classificação das famílias botânicas através do sistema Angiosperm Phylogeny Group -APG III (2009).

\subsection{Análise dos dados}

A composição florística foi analisada através da lista de espécies presentes na área registradas através da amostra, informando família, gênero e nome científico. Para interpretação da diversidade foram utilizados os índices de diversidade de ShannonWeaver $\left(H^{\prime}\right)$ e índice de equabilidade de Pielou $(J)$ (Sousa e Soares, 2013).

A estrutura horizontal foi avaliada com os parâmetros: Densidade Absoluta (DA) e Densidade Relativa (DR), Frequência Absoluta (FA) e Frequência Relativa (FR), Dominância Absoluta (DoA) e 
Dominância Relativa (DoR) além do Índice de Valor de Importância.

Para análise da estrutura diamétrica, as classes foram determinadas de acordo com os valores mínimo e máximo dos diâmetros amostrados na área, representadas em classes com amplitude de $3 \mathrm{~cm}$.

$\mathrm{Na}$ estrutura vertical, para a determinação dos estratos foi feita a divisão da amplitude de alturas em três estratos de altura total (hj) e média (hm) segundo uma amplitude de classe que foi determinada baseada no desvio padrão (S) das alturas totais, conforme as expressões abaixo:

Estrato I: $h_{j}<(h m-1 . S)$

Estrato II: $(h m-1 . S) \leq h_{j}<(h m+1 . S)$

Estrato III: $h_{j} \geq(h m+1 . S)$

Posteriormente calculou-se a Posição Sociológica Absoluta e relativa por Espécie, Lamprecht (1962); (1964), in Souza e Soares (2013).

A análise dos dados e obtenção de todos os parâmetros avaliados, foi realizada com a aplicação do Software Mata Nativa 2 (Cientec, 2006).

\section{RESULTADOS E DISCUSSÃO}

A suficiência amostral foi atendida com 22 pontos amostrais (Fig. 2). Desta forma, o levantamento é representativo da população inventariada. Analisando a curva do coletor, pode-se perceber uma estabilização a partir do ponto 22 e que o aumento no esforço amostral não alteraria a listagem de espécies amostradas.

No levantamento fitossociológico foram amostradas 12 espécies, 12 gêneros, distribuídas em 06 famílias. A família com maior riqueza foi Fabaceae, com seis espécies, destacando-se também pelo maior número de indivíduos amostrados (73 indivíduos). A família Bignoniáceae com duas espécies e as famílias Anacardiaceae, Capparaceae, Euphorbiaceae e Meliaceae, foram representadas por apenas uma espécie (Tab. 1).

Figura 2. Curva de acumulação de espécies arbóreas referida a área amostrada do Horto Florestal da UFCG - Patos.

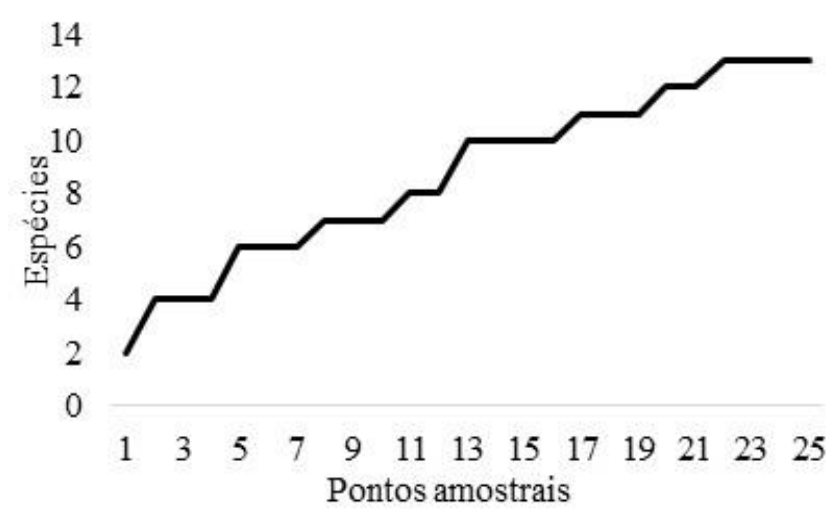

Quanto à diversidade das espécies, os valores encontrados para o índice de Shannon (H') e equabilidade de Pielou (J) foram respectivamente de 2,12 nats.ind ${ }^{-1}$ e 0,85 em área fortemente antropizada. Estes valores foram superiores aos registrados por Barbosa et al., (2012) em uma área de caatinga arbórea-arbustiva em Arcoverde - PE, que registraram o índice de Shannon (H') 2,05 nats.ind ${ }^{-1}$ e a equabilidade de Pielou, de 0,57. E por Fabricante e Andrade (2007) realizando uma análise estrutural de um remanescente de caatinga no Seridó - PB, cujos valores de Shannon e Pielou, foram respectivamente de 1,962 nats.ind ${ }^{-1}$ e 0,635. No entanto, o índice de Shannon do presente trabalho foi inferior ao registrado por Guedes et al., (2012) de 2,54 nats.ind ${ }^{-1}$, em área de caatinga preservada. Além da ação antrópica, esta diferença entre os índices também é influenciada pelas variações nos ecossistemas de caatinga, tais como: tipos de solo, relevo e pluviosidade (Santos et al., 2017). 
Tabela 1. Florística das espécies amostradas no horto florestal do Centro de Saúde e Tecnologia Rural - CSTR/UFCG, Campus de Patos, PB.

\begin{tabular}{lll}
\hline Família & \multicolumn{1}{c}{ Nome Científico } & Nome comum \\
\hline Anacardiaceae & Myracrodruon urundeuva Allemão & Aroeira \\
Bignoniaceae & Tabebuia aurea (Silva Manso) Benth. \& Hook. f. ex S. Moore & Craibeira \\
& Handroanthus impetiginosus (Mart. ex DC.) Mattos & Ipê roxo \\
Capparaceae & Cynophalla flexuosa (L.) J. Presl & Feijão Bravo \\
Euphorbiaceae & Jatropha molíssima (Pohl) Baill. & Pinhão \\
Fabaceae & Prosopis juliflora (Sw.) DC. & Algaroba \\
& Anaderanthera colubrina (Vell.) Brenon & Angico \\
& Poincianella pyramidalis (Tul.) L.P.Queiroz. & Catingueira \\
& Mimosa tenuiflora (Willd.) Poir. & Jurema preta \\
& Leucaena leucocephala (Lam.) de Wit & Leucena \\
Meliaceae & Bauhinia cheilantha (Bong.) Steud. & Mororó \\
\hline
\end{tabular}

As famílias mais representativas foram a Fabaceae e Bignoniaceae, com $73 \%$ e $10 \%$ dos indivíduos amostrados. Outros estudos realizados no semiárido nordestino também apontam que estas duas famílias estão presentes na maioria dos levantamentos florísticos e fitossociológicos, de forma predominante, o mesmo registrado por Leite et al., (2015) em caatinga serrana, município de Teixeira-PB e Santos et al., (2017), realizando estudos sobre a florísticafitossociologia e potencial madeireiro em área de caatinga submetida a manejo florestal, também na microrregião de Teixeira, caracterizaram a família Fabacea como bem representada em número de espécies e indivíduos. Medeiros et al., (2018) também identificaram esta família com importante participação no número de indivíduos amostrados em área de caatinga, na microrregião de Patos-PB.
Em dados obtidos por Fabricante e Andrade (2007) e Souza et al., (2018), a família Fabaceae também apresentou maior número de espécies, sendo semelhante ao encontrado neste trabalho. As espécies da família Fabaceae são caracterizadas por apresentarem boa fixação de nitrogênio e possuir elevado teor de proteínas, favorecendo a fertilidade dos solos (Freitas et al., 2011). Como aptidão prioritária de uso energético da caatinga, as espécies florestais que fazem parte destas famílias são aptas como fontes de energia e agregam renda para os produtores rurais (Silva et al., 2008; Francelino et al., 2003).

Na tabela 2 estão representados os parâmetros fitossociológicos com as espécies listadas em ordem decrescente do valor de importância (VI). 
Tabela 2. Estrutura horizontal das espécies amostradas no horto florestal do Centro de Saúde e Tecnologia Rural -

CSTR/UFCG, Campus de Patos, PB.

\begin{tabular}{lcccccccccc}
\hline \multicolumn{1}{c}{ Nome } & N & AB & DA & DR & FA & FR & DoA & DoR & VC (\%) & VI (\%) \\
\hline P. juliflora & 28 & 0,4808 & 322,77 & 28 & 52 & 20,63 & 5,542 & 44,84 & 36,42 & 31,16 \\
L. leucocephala & 18 & 0,0718 & 207,495 & 18 & 36 & 14,29 & 0,828 & 6,7 & 12,35 & 12,99 \\
M. tenuiflora & 11 & 0,1063 & 126,802 & 11 & 32 & 12,7 & 1,225 & 9,91 & 10,45 & 11,2 \\
T. aurea & 9 & 0,1234 & 103,747 & 9 & 28 & 11,11 & 1,423 & 11,51 & 10,26 & 10,54 \\
P. pyramidalis & 8 & 0,1127 & 92,22 & 8 & 20 & 7,94 & 1,299 & 10,51 & 9,26 & 8,82 \\
M. urundeuva & 8 & 0,075 & 92,22 & 8 & 28 & 11,11 & 0,864 & 6,99 & 7,5 & 8,7 \\
A. indica & 6 & 0,0269 & 69,165 & 6 & 16 & 6,35 & 0,31 & 2,5 & 4,25 & 4,95 \\
A. colubrina & 5 & 0,0429 & 57,637 & 5 & 12 & 4,76 & 0,495 & 4 & 4,5 & 4,59 \\
B. cheilantha & 3 & 0,0289 & 34,582 & 3 & 12 & 4,76 & 0,333 & 2,69 & 2,85 & 3,49 \\
J. molíssima & 2 & 0,0025 & 23,055 & 2 & 8 & 3,17 & 0,029 & 0,23 & 1,12 & 1,8 \\
H. impetiginosus & 1 & 0,0009 & 11,527 & 1 & 4 & 1,59 & 0,01 & 0,08 & 0,54 & 0,89 \\
C. flexuosa & 1 & 0,0003 & 11,527 & 1 & 4 & 1,59 & 0,003 & 0,03 & 0,51 & 0,87 \\
\hline Total & 100 & 1,0723 & 1152,749 & 100 & 252 & 100 & 12,361 & 100 & 100 & 100 \\
\hline
\end{tabular}

Sendo: N - número de indivíduos da espécie; AB - área basal; DA - densidade absoluta; DR - densidade relativa; FA frequência absoluta; FR - frequência relativa (\%); DoA - dominância absoluta; DoR - dominância relativa (\%); VC - Valor de cobertura; VI - Valor de importância.

A espécie Prosopis juliflora distribui-se amplamente no semiárido nordestino (Maia 2004), espécie esta que sobressaiu às demais, com maior valor de importância, densidade e dominância, bem como valor de cobertura $(36,42 \%)$. Comportamento semelhante também foi encontrado por Andrade et al., (2008), apontando em seu estudo, que esta espécie apresentou maior abundância em relação as demais espécies presentes na área. Assim, estes resultados demonstram que quando apresenta alta densidade de indivíduos a espécie interfere severamente no estabelecimento de espécies nativas (Pegado et al., 2006). O caráter oportunista desta espécie reflete na sua maior abundância na área, conforme reforçado por Araújo et al., (2018) em estudo realizado na mesma área, verificaram também maior predominância desta espécie no estrato regenerante, e ausência expressiva de espécies nativas.

A segunda espécie em valor de importância foi a Leucaena leucocephala, também com o segundo maior número de indivíduos amostrados, representando também o segundo maior valor de cobertura (12,35\%). Costa e Durigan (2010) caracterizam esta espécie como ruderal, pela sua capacidade de ocupação de áreas perturbadas. Podendo formar maciços e dificultar a ocupação de áreas por espécies nativas.

Apenas com o terceiro maior valor de importância, foi identificada a Mimosa tenuiflora $(11,20 \%)$, como primeira representante das espécies nativas. Esta espécie é de ampla distribuição no semiárido com relevante importância econômica e ecológica (Bakke et al., 2006). Além da adaptabilidade 
de ocorrência, como registro da elevada abundância desta espécie em áreas em processo de desertificação e em áreas mais conservadas, conforme estudo de Souza et al., (2015).

A T. aurea apresentou nove indivíduos, porém com segundo maior valor de dominância relativa (11,51\%), diferenciando-se da $L$. leucocephala (6,70\%). A soma dos indivíduos $P$. juliflora, $L$. leucocephala, M. tenuiflora e T. aurea, corresponderam a $66,0 \%$ dos indivíduos amostrados. A presença destas espécies nativas na área, tendo a $M$. tenuiflora e T. aurea como principais representantes em valor de importância, auxilia na recuperação da vegetação antropizada, cujas características causam alteração no ambiente, fornecendo condições ideais para instalação de espécies consideradas tardias (Silva 2018).

As espécies nativas que apresentaram maior frequência relativa foram $M$. tenuiflora $(12,07 \%)$ e $M$. urundeuva (11,11\%). Sendo de considerável importância no bioma caatinga, como fontes de lenha, carvão vegetal, forragem animal e também de uso medicinal (Alves et al., 2017).

Segundo Ferraz et al., (2014), em razão da espécie $M$. urundeuva demonstrar comportamento competidor, a espécie apresenta uma boa adaptação em áreas conservadas e antropizadas. Dessa maneira, pelo fato da $M$. urundeuva aparecer entre as 10 espécies com maior VI na área em estudo, significa que a floresta está em processo de sucessão (Batista 2017).

$\mathrm{Na}$ distribuição diamétrica, os indivíduos foram organizados em classes figura 3. As maiores concentrações dos indivíduos estão nas duas primeiras classes, tendo o comportamento de J-invertido. A soma dos indivíduos presentes nas duas primeiras classes (menores classes) de diâmetro representa $54,0 \%$ dos indivíduos amostrados.
Figura 3. Distribuição diamétrica dos indivíduos amostrados no horto florestal do Centro de Saúde e Tecnologia Rural - CSTR/UFCG, Campus de Patos, PB.

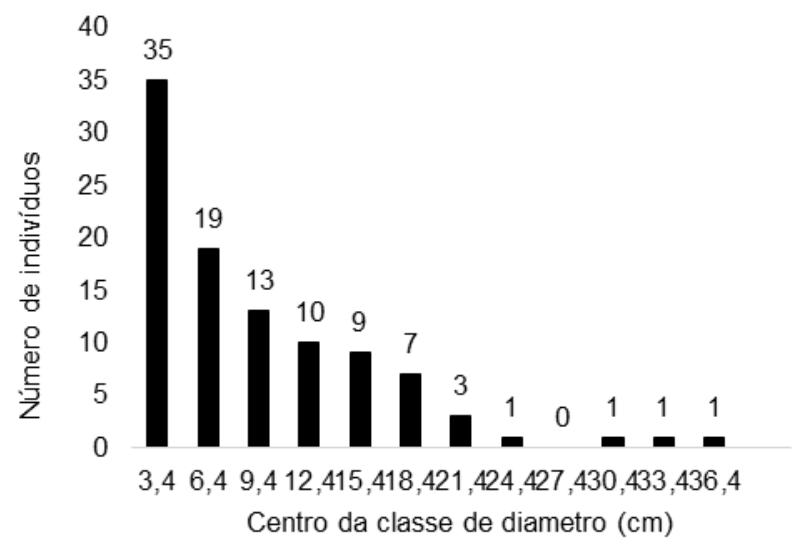

Os resultados encontrados em outros estudos realizados no bioma caatinga (Moreira 2014; Alves et al., 2017; Medeiros et al., 2018), seguiram a mesma tendência do J-invertido, o qual demonstra uma maior quantidade de indivíduos nas classes menores de diâmetro, sendo uma característica de florestas inequiâneas que estão em estado de reestabelecimento, pois sofreram intervenções antrópicas e longos períodos de seca.

$\mathrm{Na}$ estrutura vertical, as alturas dos indivíduos foram distribuídos em três classes de altura (Fig. 4), de maneira que a maior concentração ocorreu na classe central, com $62 \%$ dos indivíduos amostrados.

Figura 4. Distribuição de alturas dos indivíduos amostrados no horto florestal do Centro de Saúde e Tecnologia Rural CSTR/UFCG, Campus de Patos, PB.

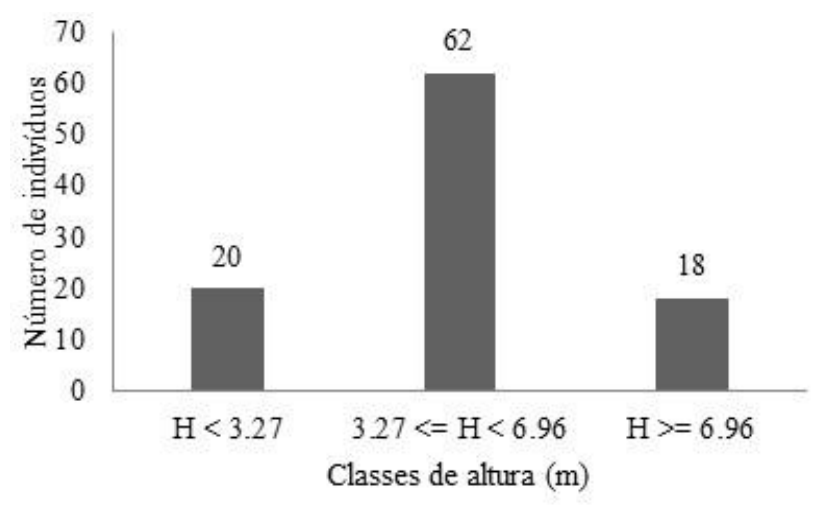


Logo, dos 100 indivíduos amostrados com base na posição sociológica, $20 \%$ compõem o estrato inferior $(\mathrm{H}<3.27), 62 \%$ pertencem ao estrato médio $(3.27 \leq \mathrm{H}<6.96)$ e $18 \%$ ao estrato superior $(\mathrm{H} \geq 6.96)$.

Quanto a posição sociológica, as espécies foram descritas em ordem decrescente quanto à posição sociológica absoluta (PSA) e relativa (PSR), conforme tabela 3 .

Dessa forma, observa-se que a espécie $P$. juliflora representa majoritariamente o estrato médio com 26,58\% dos indivíduos, em sequência $L$. leucocephala com 21,59\%. Segundo Souza et al., (2018), por representarem as espécies com os maiores valores, isto indica que essas espécies apresentam maior aptidão de serem encontradas em todos os estratos e se adaptarem as condições ambientais presentes na área.

Tabela 3. Posição Sociológica absoluta e relativa das espécies amostradas em ordem decrescente, no horto florestal do Centro de Saúde e Tecnologia Rural CSTR/UFCG, Campus de Patos, PB.

\begin{tabular}{lcc}
\hline \multicolumn{1}{c}{ Nome } & PSA & PSR \\
\hline P. juliflora & 575,36 & 26,58 \\
L. leucocephala & 467,3 & 21,59 \\
M. tenuiflora & 263,51 & 12,17 \\
P. pyramidalis & 215,17 & 9,94 \\
A. indica & 156,4 & 7,22 \\
T. aurea & 142,18 & 6,57 \\
M. urundeuva & 134,6 & 6,22 \\
B. cheilantha & 67,3 & 3,11 \\
A. colubrina & 65,4 & 3,02 \\
J. molissima & 58,77 & 2,71 \\
H. impetiginosus & 9,48 & 0,44 \\
C. flexuosa & 9,48 & 0,44
\end{tabular}

Sendo: PSA - posição sociológica absoluta e PSR - posição sociológica relativa.
Assim, a $P$. julifora nesse local em estudo é considerada uma espécie invasora, apresentando maior valor quanto à PSR, sendo similar ao trabalho de Bezerra e Pereira (2017) e Pegado et al., (2006) que aponta um alto valor de indivíduos da espécime e a caracteriza como sendo uma espécie que interfere em ambientes já colonizados reduzindo o estabelecimento de espécies nativas.

Estudos realizados em área de caatinga com análise do índice de posição sociológica absoluta (PSA) e relativa (PSR) ainda são escassos, o que dificulta a comparação dos resultados encontrados neste estudo com outros trabalhos.

\section{CONCLUSÃO}

As famílias Fabaceae e Bignoniaceae, apresentaram a maior representatividade de número de espécies e indivíduos, sendo assim as responsáveis pela maior riqueza da área. Evidenciando a predominância de espécies exóticas invasoras, destacando-se a $P$. juliflora e a L. leucocephala.

As espécies a P. juliflora, L. leucocephala e M. tenuiflora são as mais importantes para a área estudada, maiores valor de cobertura e de importância. Evidencia-se na área a predominância dessas espécies invasoras que afetam o desenvolvimento $\mathrm{e}$ regeneração das espécies nativas na área.

A distribuição diamétrica da área reflete o comportamento de populações naturais, caracterizando um J-invertido, com alta concentração de indivíduos nas classes inferiores.

A estratificação vertical apresenta boa taxa de representantes nos três estratos, com maior estimativa de produção na classe de maiores alturas, concentrando essa produção em poucos indivíduos, bem desenvolvidos.

Todos os autores declararam não haver qualquer potencial conflito de interesses referente a este artigo. 


\section{REFERÊNCIAS}

ALVES, L.L.B; ALVES, A.R.; BARRETO, F.R.S.; HOLANDA, A.C. Análise florística e estrutural de uma área de caatinga preservada no município de Mossoró/RN. Conexões-Ciência e Tecnologia. v.11, n.1, p.8-15, 2017.

ANDRADE, L.A.; FABRICANTE, J.R.; OLIVEIRA, F.X. Invasão biológica por Prosopis juliflora ( $S w$.) DC.: impactos sobre a diversidade e a estrutura do componente arbustivo-arbóreo da caatinga no estado do Rio Grande do Norte, Brasil. Acta Botanica Brasílica. v.23, n.4, 2008.

ANDRADE, L.A.; PEREIRA, I.M.; LEITE, U.T.; BARBOSA, M.R.V. Analise da cobertura de duas fitofisionomias de Caatinga, com diferentes históricos de uso, no município de São João do Cariri, estado da Paraíba. Cerne. v.11, n.3, p.253-262, 2005.

APG III. An update of the Angiosperm Phylogeny Group classification for the orders and families of flowering plants: APG III. Botanical Journal of the Linnean Society, v.161, n.2, p.105-121, 2009.

ARAÚJO, A.N.; BAKKE, I.A.; VASCONCELOS, G.S.; SILVA, R.M.; MARTINS, K.B.S.; FERNANDES, S.P.S. Regeneração Natural de algaroba (Prosopis Juliflora (Sw.) Dc.) no Horto Florestal do CSTR/UFCG, Patos - PB. Revista ACSA. v.14, n.4, p.318-324, 2018.

BAKKE, I.A., FREIRE, A.L.O., BAKKE, O.A., ANDRADE, A.P., BRUNO, R.L.A. Water and sodium chloride effects on Mimosa tenuiflora (Willd.) Poiret seed germination. Revista Caatinga. v.19, n.3, p.261267, 2006.

BARBOSA, M.D.; MARANGON, L.C.; FELICIANO, A.L.P.; FREIRE, F.J.; DUARTE, G.M.T. Florística e fitossociologia de espécies arbóreas e arbustivas em uma área de caatinga em Arcoverde, PE, Brasil. Rev. Árvore. v.36, n.5, p.851$858,2012$.

BATISTA, W.C.A. Composição florística e estrutura fitossociológica em caatinga arbórea no Sudoeste da Bahia. Vitória da Conquista, BA. Dissertação de Mestrado. Universidade Estadual do Sudoeste da Bahia - UEAB; 2017.

BRASIL. Ministério de Minas e Energia. 2005. Projeto cadastro de fontes de abastecimento por água subterrânea. Diagnóstico do município de Patos, estado da Paraíba. Disponível em: http://www.cprm.gov.br/publique/Hidrologia/Projetos /Projeto-Cadastramento-de-Fontes-de-
Abastecimento-por-Agua-Subterranea-3500.html.

Acesso em: 17 de jul. 2019.

BEZERRA, C.S.; PEREIRA, J.G. Diversidade da Vegetação Arbórea em uma Área de Caatinga no Município de Monteiro-PB. Cadernos de Cultura e Ciência. v.16, n.1, p.100-108, 2017.

BRITO A.; FERREIRA, M.Z.; MELLO, J.M.; SOARES, J.R.S.; OLIVEIRA, A.D.; WEIMAR, F.A. Comparação entre os métodos de quadrantes e prodan para análises florística, fitossociológica e volumétrica. Cerne. v.13, n.4, p.399-405, 2007.

CHAVES, A.D.C.G.; SANTOS, R.M.S.; SANTOS, J.O.; FERNANDES, A.A.; MARACAJÁ, P.B.A importância dos levantamentos florístico e fitossociológico para a conservação e preservação das florestas. Revista ACSA. v.9, n.2, p.43-48, 2013.

CIENTEC. Software Mata Nativa 2: Sistema para Análise Fitossociológica, Elaboração de Inventários e Planos de Manejo de Florestas Nativas. Viçosa, cientec; 2006.

COSTA, J.N.M.N.D.; DURIGAN, G. Leucaena leucocephala (Lam.) de Wit (Fabaceae): invasora ou ruderal?. Revista Árvore. v.34, n.5, p.825-833, 2010.

COTTAM, G.; CURTIS, J.T. The use fo distance measures in phytosociological sampling. Ecology. v.37, n.3, p.451-460, 1956.

DUQUE, J. G. O Nordeste e as lavouras xerófilas. 4 ed., Fortaleza, Banco do Nordeste do Brasil; 2004.

Fabricante, J.R.; Andrade, L.A.; Análise estrutural de um remanescente de caatinga no Seridó Paraibano. Oecologia Brasiliensis. v.11, n.3, p.341-349, 2007.

FERRAZ, J.S.F.; FERREIRA, R.L.C.; SILVA, J.A.A.; MEUNIER, I.M.J.; SANTOS, M.V.F. Estrutura do componente arbustivo-arbóreo da vegetação em duas áreas de caatinga, no município de Floresta, Pernambuco. Revista Árvore. v.38, n.6, p.1055-1064, 2014.

Flora do Brasil 2020 em construção. Jardim Botânico do Rio de Janeiro. Disponível em: <http://floradobrasil.jbrj.gov.br/>. Acesso em: set. 2018.

FRANCELINO, M. R.; FERNANDES FILHO, E.I.; RESENDE, M.; LEITE, H. G. Contribuição da caatinga na sustentabilidade de projetos de assentamentos no sertão norte-rio-grandense. Revista Árvore. v.27, n.1, p.79-86, 2003. 
FREITAS, A.D.S.; SILVA, T.O.; MENEZES, R.S.C.; SAMPAIO, E.V.S.B.; ARAÚJO, E.R.; FRAGA, V.S. Nodulação e fixação de nitrogênio por forrageiras da caatinga cultivadas em solos do semiárido paraibano. Revista Brasileira de Zootecnia. v.40, n.9, p.18561861, 2011.

GUEDES, R.S.; ZANELLA, F.C.V.; COSTA JUNIOR, J.E.V.; SANTANA, G.M.; SILVA, J.A. Caracterização florístico-fitossociológica do componente lenhoso de um trecho de caatinga no semiárido paraibano. Revista Caatinga. v.25, n.2, p.99-108, 2012.

LEAL， I.R.; SILVA， J.M.C.; TABARELLI, M, LACHER JUNIOR, T.E. Mudando o curso da conservação da biodiversidade na Caatinga do Nordeste do Brasil. Revista Megadiversidade. v.1, n.1, p.139-146, 2005.

LEITE, J.A.N.; ARAÚJO, L.V.C.; ARRIEL, E.F.; CHAVES, L.F.C.; NÓBREGA, A.M.F. Análise quantitativa da vegetação lenhosa da caatinga em Teixeira, PB. Pesquisa Florestal Brasileira, v.35, n.82, p.89-100, 2015.

MAIA, G.N. Caatinga: árvores e arbustos e suas utilidades. 1 ed., São Paulo, D \& Z Computação Gráfica e Editora; 2004.

MEDEIROS, F.S.; SOUZA, M.P.; CERQUEIRA, C.L.; ALVES, A.R.; SOUZA, M.S.; BORGES, C.H.A. Florística, fitossociologia e modelagem da distribuição diamétrica em um fragmento de Caatinga em São Mamede-PB. ACSA. v.14, n.2, p.85-95, 2018.

MITCHELL K. Quantitative analysis by the pointcentered quarter method. Geneva: Departament of Mathematics and Computer Science, 2015. Disponível em: $\quad$ http://people.hws.edu/mitchell/PCQM.pdf. Acesso: 12 set. 2019.

MOREIRA, F.T.A. Florística, fitossociologia e corte seletivo pelo método BDQ em uma área de caatinga, no município de São José de Espinharas - PB. Dissertação de Mestrado. Universidade Federal de Campina Grande - UFCG; 2014.

NDAGIJIMANA, C.; PAREYN, F.G.C.; RIEGELHAUPT, E. Uso do solo e desmatamento da caatinga: um estudo de caso na Paraíba e no Ceará Brasil. Estatística Florestal da Caatinga, v. 2, Associação Plantas do Nordeste, Recife. 2015.
OLIVEIRA, G.S.; CAVALCANTI, F.J.B.; MELO, L.A.; MONTE, M.A. O método de quadrantes para estimativa de variáveis quantitativas em planos de manejo na Amazônia. Cerne. v.21, n.4, p.683-691, 2015.

PEGADO, C.M.A.; ANDRADE, L.A.; FÉLIX, L.P.; PEREIRA, I.M. Efeitos da invasão biológica de algaroba - Prosopis juliflora (Sw.) DC. sobre a composição e a estrutura do estrato arbustivo-arbóreo da caatinga no Município de Monteiro, PB, Brasil. Acta Botanica Brasílica. v.20, n.4, p.887-898, 2006.

PESSOA, M.F.; GUERRA, A.M.N.M.; MARACAJÁ, P.B.; LIRA, J.F.B.; DINIZ FILHO, E.T. Estudo da cobertura vegetal em ambientes da Caatinga com diferentes formas de manejo no Assentamento Moacir Lucena, Apodi - RN. Revista Caatinga. v.21, n.3, p.40-48. 2008.

SANTOS, W.S.; HENRIQUES, I.G.N.; SANTOS, W.S.; RAMOS, G.G.; VASCONCELOS, G.S.; VASCONCELO, A.D.M. Análise florísticafitossociológica e potencial madeireiro em área de caatinga submetida a manejo florestal. ACSA. v.13, n.3, p.203-211, 2017.

SILVA, F.T. Análise fitossociológica e florística do bioma caatinga no município de Aparecida - PB. Dissertação de Mestrado. Universidade Federal de Campina Grande - UFCG; 2018.

SILVA, L.B.; SANTOS, F.A.R.; GASSON, P.; CUTLER, D. Anatomia e densidade básica da madeira de Caesalpinia pyramidalis Tul. (Fabaceae), espécie endêmica da caatinga do Nordeste do Brasil. Acta Botânica Brasílica. v.23, n.2, p.436-445. 2008.

SOUZA, A.L. SOARES, C.P.B. Florestas nativas: estrutura, dinâmica e manejo. 1 ed., Viçosa, Ed. UFV; 2013.

SOUZA, B.I., MENEZES, R., CÁMARA ARTIGAS, R. Efeitos da desertificação na composição de espécies do bioma Caatinga, Paraíba/Brasil. Investigaciones Geográficas (Boletín). n.88, Instituto de Geografía, UNAM, México, pp. 45-59. 2015.

SOUZA, S.R.; FERREIRA, W.C.; GUILHERME, F.A.G. Caracterização florística e fitossociológica de mata de galeria do córrego Santa Rosa, em de Jataí- GO. Global Science and Technology. v.11, n.3, p.147-164, 2018. 